\title{
Alterações do conteúdo aéreo pulmonar em bovinos abatidos em estabelecimentos industriais
}

\section{Alterations of pulmonar airy content in slaughtered cattle at industrial estabilishment}

\author{
Zander Barreto Miranda*
}

\begin{abstract}
Resumo
São apresentadas e discutidas as lesões pulmonares que mais freqüentemente ocorrem em bovinos abatidos para consumo em matadouros frigoríficos com Inspeção Federal.
\end{abstract}

Em 4.552 bovinos, 2.173 mostraram lesões pulmonares na inspeção post mortem; foram rejeitados 589 pulmões com afecções por arejamento, representadas por 426 enfisemas e 172 atelectasias.

Palavras-chave: patologia pulmonar; bovinos; inspeção sanitária.

\section{Introdução}

A inspeção sanitária de carnes tem permitido verificar a ocorrência freqüente de lesões pulmonares nos bovinos abatidos em estabelecimentos industriais que, quase sempre, se associam a reflexos negativos para a economia animal. A função respiratória se dá no aparelho orgânico mais aberto ao meio exterior e implica trazer para si (aspiração), suspensos na atmosfera, os mais diversos agentes de doenças. Por isso, na maioria dos estados de debilidade orgânica geral, quando há queda das defesas naturais gerais e, conseqüentemente, do aparelho respiratório - barreira muco-ciliar e fagocitose por pneumócitos alveolares III (King, 1997) - este é o mais vulnerável e o primeiro a se comprometer como sede de enfermidades, inclusive aéreas, primariamente ou como complicadoras.

Na rotina de inspeção de carnes em matadouros é dedicada uma atenção especial aos pulmões, sendo examinados individualmente e procurando correlacionar-se qualquer alteração que apresentem à possível envolvimento de outros órgãos e mesmo a eventuais reflexos na carcaça. Na inspeção ante mortem nem sempre se consegue identificar sintomas e alterações do aparelho respiratório que justifiquem a șeparação do animal para um exame mais acirrado no seqüestro (Thornton, 1968), sendo as alterações do trato respiratório quase sempre identificadas na sala de matança, em virtude da maioria das afecções ser de evolução crônica (Santos, 1979) e, por isso, quase sempre, sem um reflexo clínico correspondente.

Levantar, estabelecer e discutir elementos de orientação anátomo-patológica, macro e microscópica, das afecções bronco-pulmonares ligadas ao arejamento em bovinos batidos para consumo em estabelecimentos industriais.

\section{Material e Métodos}

A casuística compreendeu pulmões com os respectivos brônquios, traquéia e linfonodos, de 4.552 bovinos machos e fêmeas, com 1 a 5 anos de idade, procedentes de várias regiões criatórias do país, abatidos em matadouros do Rio de Janeiro e Rio Grande do Sul, e apreendidos na linha de inspeção pelo Serviço de Inspeção Federal - DIPOA - do MARÁ.

A partir da inspeção macroscópica, os pulmões condenados tinham lesões registradas em protocolos individuais, com resenha, histórico e origem. Paralelamente, era feita uma documentação fotográfica.

Amostras representativas das lesões eram imediatamente colhidas em solução salina de formol a $10 \%$, remetidas ao Serviço de Anatomia Patológica Prof. Jefferson Andrade dos Santos/UFF, para a histotécnica por inclusão em parafina e coloração pelo HxE, tricrômicro de Gomori e outros, quando necessário.

\section{Resultados e discussão}

Dos 4.552 bovinos abatidos e examinados, 2.173 tinham comprometimento pulmonar, sendo que 589 apresentavam alterações do conteúdo aéreo: 426 enfisemas e 172 atelectasias.

Os enfisemas, distinguidos nos tipos alveolar, intersticial e subpleural, tiveram a predominância do primeiro tipo, confirmando Santos (1979). Este tipo estava representado por áreas elevadas, pálidas, secas e mais crepitantes devido à distensão provocada pelo excesso de arejamento, conforme descrito por King (1997). A lesão alveolar, em sendo aérea, apresentava limites bem nítidos da unidade

*Departamento de Tecnologia dos Alimentos, Faculdade de Veterinária, UFF. Rua Vital Brazil Filho, 64 - 24230-340, Santa Rosa, Niterói-RJ. 
lobular com outras normais contíguas. Algumas vezes, as unidades lobulares contíguas àquelas enfisematosas exibiam sinais de atelectasia, o que poderia significar que esta lesão, sem arejamento e afuncional, tenha sido a causa de um enfisema colateral por desvio e sobrecarga aérea. Ao corte, as áreas enfisematosas eram resistentes e esponjosas.

À luz da microscopia, o processo se traduzia por ampliação dos sacos alveolares, algumas vezes acompanhada de hipertrofia das paredes persistentes; outras vezes, ao lado de patologias diversas (atelectasias, bronquiectasias etc.)

O tipo intersticial, também denominado interlobular, traduz-se pela presença de ar no tecido interlobular e, associado ou não, também sob a pleura, o que, na concepção de Santos (1979), constitui o tipo subpleural (bolhoso). Consoante com nossos registros, este autor o descreve com tabique brilhante, ocupado por bolhas de tamanho variável que lembram as contas de um rosário.

King (1997) atribuem a presença do processo ao bovino abatido sem prévia insesibilização (método de Köscher). Desta opinião participam Thornton (1968) que, juntamente com Wilson (1970), admite sua maior freqüência em vacas velhas.
Em nosso estudo, observamos que o uso inadequado da técnica de insensibilização corresponde a um dos fatores determinantes do enfisema pulmonar, se instalando no período pré-agônico.

A microscopia evidenciou uma distensão do interstício interlobular pelo ar interposto, confirmando o aspecto lobulado da superfície pulmonar, descrito classicamente.

A falta de arejamento de bronquíolos terminais e respiratórios e alvéolos, a atelectasia, se apresenta como áreas deprimidas nos pulmões, de aspecto "cárneo", não crepitantes e positivas no teste de "docimasia hidrostática".

A exemplo de Oghiso et al. (1976), que descreveram o processo associado a outras afecções, os nossos achados se apresentaram ao lado de fibrose pleural, enfisemas alveolar colateral e intersticial, fibrose interbronquial, congestão alveolar, bronquite verminótica e outras, bronquiectasia e pleurite.

Os enfisemas foram, em nosso trabalho, a segunda afecção mais frequente entre os achados de sala de matança, reafirmando Kamborage et al.(1995).

\begin{abstract}
Are presented and discussed the pulmonary lesions found frequentely in cattle from slaughterhouses with sanitary inspection. From 4.552 slaughtered and examined cattle, 2.173 had pulmonary diseases detected at post-mortem inspection. From 589 affected lungs by airing, 426 had emphysemas and 172 had atelectasis.
\end{abstract}

Keywords: pulmonary pathology; bovine; inspection sanitary.

\section{Referências bibliográficas}

BRASIL-MINISTÉRIO DA AGRICULTURA - Regulamento de Inspeção Industrial e Sanitária de Produtos de Origem Animal. Decreto no 30.691, de 29 de março de 1952. Rio de Janeiro. Serviço de Informações Agrícolas, 1962.

KAMBORAGE, D.M., KIMERA, S.I., KAZMALA, R.R. \& MAFWERW, B.M. Disease conditions responsible for condenation of carcasses and organs in shorthorn Zebu cattle slaughtered in Tanzania. Preventive Vet. Med., v. 22, p. 249-255, 1995.

KING, W.N.; HUNT,D.R. \& JONES, C.T. Veterinary Pathology, 6. ed. New York: Williams \& Wilkins, 1997.
OGHISO, U., YAMAMOTO, K., GOTO, N., TAKAHASHI, R. \& FULIWARA, K. Pathological studies on bovine pneumonia in special reference to isolamento of Mycoplasma $s p$. Japanese J. of Vet. Science, v. 38, n. 1, p. 15-24, 1976.

SANTOS, J.A. Patologia especial dos animais domésticos: mamíferos e aves. 2. ed. Rio de Janeiro : Interamericana, 1979.

THORNTON, C.P. Compêndio de Inspeção de Carnes, incluindo Coelhos e Aves. Fremong, 1968.

WILSON, P.E. Inspección práctica de la carne. Acribia, Zaragoza, 1970. 